\title{
THE IMPACT OF TRAFFIC LAW ENFORCEMENT ON ROAD ACCIDENT FATALITIES IN BOTSWANA
}

\author{
THUSO MPHELA \\ mphelat@mopipi.ub.bw \\ Department of Management, Faculty of Business \\ University of Botswana
}

\begin{abstract}
Botswana has one of the highest rates of increase in road traffic accidents and fatalities in the world. The amendment of road laws came with stricter penalties for road offences which included higher fines and longer jail terms. This study uses multiple regression analysis subjecting variables to backward stepwise regression with a view to assessing the impact traffic law enforcement has had on fatalities in Botswana after the review of the Traffic Act of Botswana in 2008. The study uses secondary data and interview data obtained from law enforcers. The findings reveal that the enforcement of the new road laws has achieved little in the reduction of fatalities. Increasing the minimum driver licensing age may be a panacea to road accidents. Licensed drivers in the age group 30 to 45 years have the lowest rate of fatalities. The study questions the ability of punitive policies (i.e. road fines) to reduce fatalities. It offers that driver behaviour should be studied to come up with relevant policies.
\end{abstract}

\section{INTRODUCTION}

Africa remains one of the lowest contributors to global road fatalities. However, the fatality rates are growing. South Africa and Nigeria account for more than half of the total number the continent's road fatalities chiefly because of the two countries' high level of motorisation and larger populations compared to most other African countries. In terms of the fatality rates per 100000 population, Swaziland registered 31, Botswana 28 and South Africa 27 in 1996 (Jacobs, Aeron-Thomas \& Astrop, 2000). As at 2008 road accidents are the second largest contributor to the death toll after HIV/AIDS in Botswana. In the period 19751998 Botswana recorded a 383.8\% increase, the highest in the world, in death per 10000 population while the second worst record in Africa was by Lesotho who registered a $192.8 \%$ increase (Peden, Scurfield, Slit, Mohan, Hyder, Jarawan \& Mathers, 2004). The World Health Organization (WHO) predicts that fatalities will grow by $80 \%$ by the year 2020 (Peden et al., 2004). According to the World Bank (Road Safety), 70\% of 1.7 million people who die every year as a result of road accidents are from developing economies. As a developing economy, Botswana faces challenges managing the impact of road accidents on the lives of its citizens and the economy. Substantial amounts of money go into compensation for the injured and lives lost and also in the maintenance of damaged cars and third party assets. 
Laws and policies are enacted by legislators and enforced by law-enforcement institutions particularly the police. In 2008 through the amendment of the Traffic Act No. 27 of 2008, Botswana enacted stringent road penalties against motorists breaking the country's road laws. Furthermore a 30\% levy on alcohol was instituted in 2008 to reduce among other things abuse of alcohol by drivers (Pitso \& Obot, 2011). Zietlow (2006) attributes the continued escalation of road accidents and fatalities to 'lack of awareness of the road safety problem in the public, the political and professional arenas; lack of institutional capacity and of adequately trained and motivated staff; and insufficient funding of road safety systems'. He further stresses the importance of funding and that urgent attention needs to be paid to this issue. The objective of this paper is to determine what impact enforcement of the new road laws has had in the first year of implementation.

\section{LITERATURE REVIEW}

A large proportion of road traffic accidents are as a result of road-user behaviour and more specifically, accidents occur because of the decisions taken by road users to disobey or break the road rules, commonly referred to as human error. Accident rates and compliance are inversely related. Law enforcement agencies like the traffic police come up with strategies including use of penalties to ensure road rules are obeyed and compliance improves. Aparacio, Arenas, Mira and Páez (2011) attribute the significant success of the penalty point systems to the 'gradual stepping up' of surveillance in Spain. Rothengatter (1982) supports this view, i.e. that police surveillance can significantly improve compliance. This is evidence that sustained law enforcement plays a critical role in reduction of road accidents and fatalities.

\section{Botswana accident trends}

The Botswana economy has consistently grown since independence in 1966. For the period under review (2007-2009), the economy declined in 2008/09 because of the fall in diamond trade during the global economic crisis. Looking back at accident trends in Botswana (Table 1), the year 1982 registered the highest increase in the number of accidents and casualties of $54.4 \%$ and $71.7 \%$ respectively. The corresponding increase in fatalities (39.8\%) is also high and the highest since 1981. There are a number of reasons why this could be the case: accidents were increasing from a small base which blows up the result; reporting and recording had improved from the base year; or simply that compliance was very low. This trend repeated itself in 1988 and 1989 in the increase of fatalities after a huge drop in 1986 of $38.9 \%$. 1986 presents a very interesting statistic; even though accidents increased by more than $40 \%$, casualties fell by almost $39 \%$ only to achieve an $8 \%$ reduction in fatalities. Increase in the number of registered vehicles has been consistent in the one digit region averaging $8.8 \%$ since 1981. The vehicle population has grown from 34698 in 1981 to 359223 in 2009. This is a growth of 935\% over the last 28 years. On the other hand human population was growing at around 3\% over the years from 941027 in 1981 to 1798372 
in 2009. Accidents per 1000 vehicles exceeded the 100 mark in 1991 and the years 1998 to 2001 also recorded over 100. Fatalities per 10000 vehicles stayed in the 40s in 1988 to 1993 and it gradually dropped to 13.2 by the year 2009 .

Table 1: Accident trends in Botswana (1981-2010)

Source: MVA Fund, Botswana.

\begin{tabular}{|c|c|c|c|c|c|c|c|c|c|}
\hline YEAR & ACCIDENT & CASUALITY & FATAL & $\begin{array}{c}\text { REG. } \\
\text { VEHICLE }\end{array}$ & EST. POP & $\begin{array}{c}\mathrm{ACC} / 1000 \\
\text { VEH }\end{array}$ & $\begin{array}{c}\text { CAS } / 1000 \\
\text { VEH }\end{array}$ & $\begin{array}{c}\text { FAT/10000 } \\
\text { VEH }\end{array}$ & $\begin{array}{l}\text { FAT/100 } \\
\text { 000 POP }\end{array}$ \\
\hline 1981 & 1715 & 940 & 93 & 34698 & 941027 & 49.4 & 27.1 & 26.8 & 9.9 \\
\hline 1982 & 2648 & 1614 & 130 & 38451 & 975625 & 68.9 & 42 & 33.8 & 13.3 \\
\hline 1983 & 2205 & 1251 & 176 & 42479 & 1011388 & 51.9 & 29.4 & 41.1 & 17.4 \\
\hline 1984 & 3300 & 1799 & 168 & 47192 & 1048245 & 69.9 & 38.1 & 35.6 & 16 \\
\hline 1985 & 3521 & 2369 & 198 & 51678 & 1086139 & 68.1 & 45.8 & 38.3 & 18.2 \\
\hline 1986 & 4983 & 1448 & 182 & 55604 & 1125008 & 89 & 44 & 32.7 & 16.2 \\
\hline 1987 & 4515 & 1746 & 191 & 57705 & 1164893 & 78.2 & 47.6 & 33.1 & 16.4 \\
\hline 1988 & 5741 & 2923 & 262 & 64301 & 1205834 & 89.3 & 45.5 & 40.7 & 21.7 \\
\hline 1989 & 6299 & 4136 & 295 & 70030 & 1247771 & 89.9 & 59.1 & 42.1 & 23.6 \\
\hline 1990 & 7614 & 4845 & 314 & 80953 & 1290642 & 94.1 & 59.8 & 38.8 & 24.3 \\
\hline 1991 & 8381 & 4871 & 349 & 83048 & 1326796 & 100.9 & 58.7 & 42 & 26.3 \\
\hline 1992 & 9017 & 4909 & 368 & 90405 & 1378993 & 99.7 & 54.3 & 40.7 & 26.7 \\
\hline 1993 & 9161 & 5136 & 379 & 94440 & 1424502 & 97 & 54.4 & 40.1 & 26.6 \\
\hline 1994 & 9420 & 5171 & 352 & 108048 & 1458690 & 87.2 & 47.9 & 32.6 & 24.1 \\
\hline 1995 & 9536 & 5247 & 410 & 117733 & 1493699 & 81 & 44.6 & 34.8 & 27.4 \\
\hline 1996 & 10338 & 5457 & 338 & 128292 & 1529548 & 80.6 & 42.5 & 26.3 & 22.1 \\
\hline 1997 & 11882 & 5956 & 411 & 133691 & 1546725 & 85 & 44.6 & 30.7 & 26.6 \\
\hline 1998 & 14279 & 6887 & 453 & 139839 & 1598610 & 102.1 & 49.2 & 32.4 & 28.3 \\
\hline 1999 & 16922 & 8049 & 494 & 149639 & 1603847 & 113.1 & 53.8 & 33 & 30.8 \\
\hline 2000 & 16313 & 7790 & 529 & 154000 & 1642339 & 105.9 & 50.6 & 34.4 & 32.2 \\
\hline 2001 & 17125 & 7945 & 526 & 166405 & 1622129 & 102.9 & 47.7 & 31.6 & 32.4 \\
\hline 2002 & 18610 & 8014 & 520 & 186865 & 1721204 & 99.6 & 42.9 & 27.8 & 31.3 \\
\hline 2003 & 18329 & 7969 & 557 & 204228 & 1762512 & 90 & 39 & 27 & 31.6 \\
\hline 2004 & 18136 & 7840 & 532 & 225182 & 1715355 & 80.5 & 34.8 & 23.6 & 31.1 \\
\hline 2005 & 17522 & 7069 & 450 & 246681 & 1727372 & 71 & 28.7 & 18.2 & 26.1 \\
\hline 2006 & 17522 & 7069 & 429 & 267117 & 1739556 & 63.8 & 26 & 16.1 & 24.7 \\
\hline 2007 & 19487 & 7639 & 497 & 293755 & 1756651 & 66.3 & 26 & 16.9 & 28.3 \\
\hline 2008 & 20415 & 8160 & 455 & 329270 & 1776283 & 62 & 24.8 & 13.8 & 25.6 \\
\hline 2009 & 20000 & 7970 & 475 & 359223 & 1798372 & 55.7 & 22.2 & 13.2 & 26.4 \\
\hline 2010 & 18978 & 6430 & 397 & 394401 & 1800098 & 48.1 & 16.3 & 10.1 & 22.1 \\
\hline
\end{tabular}

\section{Causes of accidents}

Developing economies like Botswana have high levels of accident rates which are accounted for by many factors including road designs and most importantly driver behaviour. In Saudi Arabia over $50 \%$ of accidents are caused by drivers speeding. Other causes include not obeying road signals, and using incorrect methods of overtaking, U-turning and parking; an insignificant number was caused by alcohol (Ansari, Akdaar, Mandoorah \& Moutaery, 2000). In Korea 64\% of accidents are caused by reckless driving which includes alcohol; 
violation of traffic signals; driving too close; improper driving at intersections; and violation of pedestrian protection (Yang \& Kim, 2003). In Sindh, Pakistan, the leading causes of fatal road crashes, accounting for $31 \%$, are identified as vehicles hitting pedestrians and donkey-driven cart collisions; while 19\% are caused by speeding (Shah, Khoumbati \& Soomro, 2007). (The 'reyri', as the donkey cart is affectionately known in Pakistan is one of the prominent modes of passenger travel.) According to the Namibian MVA Fund report of 2009 'loss of control' by drivers contributed $24 \%$ to total accidents while accidents involving pedestrians accounted for $22 \%$ of the accidents during the first six months of 2009. Whereas an $8 \%$ reduction in accidents was achieved in the same period from the previous year, a $68 \%$ increase in fatalities was registered. In South Africa an average of $85 \%$ of fatal crashes that occur every year are as a result of human error including speeding and pedestrian jay-walking. Most (almost 35\%) of these accidents occur after 17.00 in Namibia and South Africa (Namibian MVA Fund Report, 2009; Gainewe \& Masangu, 2010). This is explained by the limited visibility and undesirable behaviour in the dark when human policing is limited or absent. Barengo, Mkamba, Mshana and Miettola (2006) identified speed as the leading contributor to traffic accidents in Dar es Salam followed by careless driving; mechanical defects; overtaking; road-crossing pedestrians; bad road conditions; intoxication; stray animals; crossing cyclists; and obstruction. According to Mupimpila (2008:1), a 'combination of speeding, drinking and driving has been cited as a major cause of road accidents in Botswana'. Unfortunately there is no universal definition of the cause of accidents. Elvik and Amundsen (2003) acknowledge the intricate relationships between road risk factors and road accidents and fatalities. This explains why accident reporting is often a challenging job even for road law enforcers. Consequently this could lead to wrong policies and interventions perpetuating the existing road traffic challenges. Considering the studies discussed above one may conclude that driver behaviour is the leading contributor to road accidents.

\section{Compliance}

There is little evidence to suggest that increase of traffic fines leads to compliance and reduction of fatalities. Road conditions, and type and design or engineering, and vehicle engineering also have an impact (Zajc, 1996; Constant, Salmi, Lafont, Chiron \& Lagard, 2008; Friedman, Hedeker \& Richter, 2009) but this paper makes an assumption that drivers are rational agents who would adapt their driving behaviours to the road conditions. This assumption is however challenged by Elvik (2010) who advocates for regulation of speed because of lack of driver rationality in speed choice.

Bjørnskau and Elvik's (1992) empirical study affirms the game-theoretic model that concludes that '(i) most attempts at enforcing road traffic legislation will not have any lasting effects, either on road-user behaviour or on accidents; (ii) imposing stricter penalties (in the form of higher fines or longer prison sentences) will not affect road-user behaviour; 
(iii) imposing stricter penalties will reduce the level of enforcement'. On the other hand '... (iv) implementing automatic traffic surveillance techniques and/or allocating enforcement resources according to a chance mechanism, and not according to police estimates of violation probability, can make enforcement effects last, but both alternatives are difficult to implement ...'

The effect of the above argument is that compliance only brings results if it can be sustained. A serious challenge that developing economies are faced with is shortage of resources which makes it difficult for law enforcement agencies to afford the technology and equipment that is required to make enforcement efficient. Law enforcement can also be overwhelming to enforcement agencies. Use of technologies would definitely increase the number of cases that law enforcers would have to deal with. This would challenge the human resources depth of the agencies, thus rendering the system inefficient.

At the beginning of 2008 the city of San Francisco reported a reduction by half of accidents recorded in the first quarter year on year which was attributed to the introduction of double fines ranging from US\$137 for speeding to US\$2 750 for reckless driving causing bodily harm. This is one of the few successful cases found in literature where fines resulted in such a huge decline in accidents. It is not very clear though how a direct relationship between the two variables was determined. Constant et al. (2009) attribute the decline in road mortalities in France to the change in the drivers' attitude towards road traffic safety in embracing stricter regulations. The authors bring into the picture an interesting debate that the law alone is not sufficient, but rather how well motorists receive it is what makes the difference. This is especially true when total surveillance of roads and motorists cannot be guaranteed by law enforcement. Statistics in different countries support this view as there is evidence that many accidents happen during the time when law enforcers are not on the roads, especially at night. Risa (1992) opines that there are legal regulations like 'speed limits, negligence, and liability rules' that are used to influence motorists to behave in a precautionary way. Speed limitations particularly received great support from which Neeley and Richardson Jr (2009) concluded that higher speed limits contributed to higher fatality rates. Different laws and penalties are used to shape motorists' behaviour but few countries have succeeded in this. Friedman et al. (2009) found that a 3.2\% increase in road fatalities was attributable to raised speed limits in some parts of the United States.

\section{Enforcement}

The existence of policies is not sufficient but the enforcement makes the difference. Road safety engineering, prevention campaigns and law enforcement measures are usually adopted to deal with road safety issues. Constant et al. (2008) opine that the embracing of the stricter regulations in France brought significant changes because it was coupled with enforcement. According to Richter, Friedman, Berman and Rivkind (2005) the United 
Kingdom experienced more significant drops in fatality rates than the USA by intensifying the use of speed camera networks. The professional safety report of 2009 shows a decline of traffic fatalities by $4 \%$ across the US as a result of stricter seatbelt law enforcement. It also indicates that states with a higher level of seatbelt use reported even higher reductions in fatalities. This supports the view that the more present law enforcement activities and techniques are the higher the likelihood of improving compliance by motorists which would lead to reduced road accidents and fatalities.

Sweden officially adopted a 'Vision Zero' in 1997 with a road fatality rate of not more than 400, as a strategy aimed at eliminating road accident fatalities by the year 2020 . This policy has influenced the country to take drastic measures and invest heavily in new road designs and developments. This initiative saw Sweden recording a paltry 4.9 per 100 000 deaths in 2000. Some of their new developments were reduction in speeds down to $30 \mathrm{~km} / \mathrm{h}$ and visibility by installation of fixed and mobile cameras. Tingvall (2009), Director of Traffic Safety, Swedish Road Administration, calls it a 'shift in philosophy'. 'You can't solve safety simply by placing a legal requirement on the user. Road users must follow the rules of the system but system designers - road managers, the auto industry, police and politicians - are responsible for safety within the entire system.' Law enforcers and other stakeholders should not relegate the responsibility of making roads safe to a piece of law but should rather activate the law by using available techniques. Of course this would call for government to invest resources in these initiatives.

It is evident that enforcing new laws and policies does not translate into compliance. Reduction of road accidents and fatalities however can be achieved if road-user compliance improves. The problem arises because road users do not comply voluntarily. Consequently this forces the application of law enforcement techniques. The literature indicates that increasing and sustaining enforcement increases chances of reducing road accidents and fatalities.

\section{RESEARCH STRATEGY}

\section{Data sources}

The road accident and fatalities statistics were extracted from the Central Statistics Office (CSO) of Botswana reports and the Motor Vehicle Insurance Fund of Botswana. The latter is charged with managing the fund generated from fuel levies to cover against injuries sustained or deaths arising from accidents within the borders of Botswana. Data on law enforcement in the form of registered cases was supplied by the Botswana Police Service Traffic Division. It has to be noted that collection of data in this area is a challenge for this country. In fact according to the CSO the statistics captured regarding fatalities are those recorded at the scene of the accident; no follow-up is made to hospitals for cases which the injured survives to the hospital. This means that in some cases, those who later die in 
hospital are not recorded. The data used covers a period of three years from 2007 to 2009. There are two reasons for this: 1) this is the period of interest, with 2007 forming a base and 2009 representing the effect of the revised Act in 2008; and 2) the data integrity needed is recorded from 2007. Law enforcers (police officers) were also interviewed to fill in the gaps in the data provided.

\section{Data analysis}

The dependent variable 'Fatalities' is explained by a number of variables including road offences, driver characteristics and number of registered vehicles. All variables were expressed in absolute number of cases that occurred in a month. Correlations and descriptive statistics were run to investigate causal and directional relationships between the dependent variable and independent variables. The latter were further subjected to a multicollinearity test. This was to determine the independent variables displaying high levels of correlations among themselves. A number of variables failed the test because coefficients between variables were quite high. Multiple regression analysis was used to build and estimate the models. This resulted in variables being removed one at a time while monitoring the model's significance. The variable 'others' was removed as it accounted for any miscellaneous and/or minor driver offences. The variables were further subjected to a backward stepwise regression analysis (Table 2) on SPSS to test the robustness of the model and validate it. What this process does is it subjects each variable to a statistical significance test and removes the insignificant leaving the significant variables in the model.

Table 2: Model summary (backward stepwise regression)

Model summary
\begin{tabular}{|c|c|c|c|c|}
\hline Model & R & R square & $\begin{array}{c}\text { Adjusted } \\
\text { R square }\end{array}$ & $\begin{array}{c}\text { Std. error of } \\
\text { the estimate }\end{array}$ \\
\hline 1 & .908 & .825 & .597 & 6.838 \\
\hline 2 & .908 & .825 & .634 & 6.520 \\
\hline 3 & .908 & .825 & .664 & 6.243 \\
\hline 4 & .908 & .824 & .689 & 6.009 \\
\hline 5 & .908 & .824 & .710 & 5.800 \\
\hline 6 & .907 & .822 & .727 & 5.627 \\
\hline 7 & .905 & .818 & .739 & 5.508 \\
\hline 8 & .898 & .806 & .738 & 5.522 \\
\hline 9 & .883 & .780 & .719 & 5.715 \\
\hline 10 & .871 & .758 & .707 & 5.833 \\
\hline
\end{tabular}

\section{The model}

The model (Table 3) focuses solely on efforts made to enforce road traffic regulations by Botswana. The researcher identified explanatory variables of fatalities from the literature. 
In a similar study Welki and Zlatoper (2007:209) have five variables (economic conditions; driver characteristics; government regulations; location factors; enforcement efforts). GDP is widely used as an indicator of social wellbeing including social ills (Stewart, 2005). Some variables are deliberately left out in this paper. The general model comprises the following:

Table 3: Descriptive statistics and variable correlations

\begin{tabular}{|l|c|c|c|c|c|c|c|c|c|c|c|c|}
\hline Variable & Mean & $\begin{array}{c}\text { Std. } \\
\text { Dev. }\end{array}$ & $\mathbf{1}$ & $\mathbf{2}$ & $\mathbf{3}$ & $\mathbf{4}$ & $\mathbf{5}$ & $\mathbf{6}$ & $\mathbf{7}$ & $\mathbf{8}$ & $\mathbf{9}$ & $\mathbf{1 0}$ \\
\hline $\begin{array}{l}\text { Cellphone } \\
\text { arrests }\end{array}$ & 364.64 & 262.32 & 1 & & & & & & & & & \\
\hline $\begin{array}{l}\text { Seatbelt } \\
\text { arrests }\end{array}$ & 1393.67 & 829.58 & 0.187 & 1 & & & & & & & & \\
\hline Speeding & 3337.50 & 825.11 & -0.311 & 0.243 & 1 & & & & & & & \\
\hline $\begin{array}{l}\text { Drunk driving } \\
\text { arrests }\end{array}$ & 98.50 & 42.20 & 0.320 & 0.216 & 0.148 & 1 & & & & & \\
\hline $\begin{array}{l}\text { Unlicensed } \\
\text { driver arrests }\end{array}$ & 929.42 & 174.82 & 0.49 & 0.358 & -0.004 & 0.438 & 1 & & & & & \\
\hline $\begin{array}{l}\text { Failure to } \\
\text { produce a licence }\end{array}$ & 115.89 & 33.05 & 0.619 & 0.199 & -0.072 & 0.221 & 0.733 & 1 & & & & \\
\hline Others & 6394.97 & 2966.84 & 0.677 & -0.113 & -0.287 & 0.216 & 0.703 & 0.738 & 1 & & & \\
\hline Fines & 2179.72 & 965.76 & 0.027 & -0.121 & 0.150 & 0.734 & 0.148 & -0.134 & 0.034 & 1 & & \\
\hline Fatalities & 39.69 & 10.94 & -0.278 & 0.157 & 0.452 & 0.188 & 0.331 & 0.050 & 0.008 & 0.342 & 1 & \\
\hline $\begin{array}{l}\text { Number of } \\
\text { registered } \\
\text { vehicles }\end{array}$ & 2595.69 & 530.81 & 0.476 & 0.424 & -0.087 & 0.559 & 0.583 & 0.444 & 0.466 & 0.512 & 0.325 & 1 \\
\hline
\end{tabular}

Key: Mean is calculated on the basic of monthly occurrence of each factor i.e. total incidents over 3 years divided by 36 months. All correlations calculated at the $5 \%$ significance level.

Motor vehicle fatalities $=f$ (enforcement, driver characteristics, other factors)

Motor vehicle fatalities, which is the dependent variable, is measured by the aggregate number of deaths occurring on the roads per month. The explanatory variable (enforcement) is made up of a number of sub-variables which represent interventions by the country and its traffic law enforcers. Cellphone arrests represent the number of drivers who admitted and were charged for use of mobile phones while driving. Enforcing seatbelt law has also yielded some significant results in the reduction of fatality rates (Contant et al., 2008; Professional Safety Report, 2009). Speeding and drunk driving are also a dangerous combination on the road. The effect of each one of them is noticeable and most public education messages are directed at addressing them. Variables such as 'driving without a licence' and 'failure to produce a licence' are related. Driving without a licence means somebody is not licensed to drive while failure to produce a licence means the driver is licensed to drive but is not in possession of the licence at the time of police intervention. In increasing fines the authorities expected this to encourage safe driving behaviour thereby 
reducing accidents. 'Others' refers to minor traffic offences. 'Registered vehicles' refers to the number of vehicles registered on a monthly basis during the period under study. Age has been a critical variable in transport research, especially significant in the young and the elderly. In Botswana two categories '18-29' and '30-45' years account for $94 \%$ of the driver population licensed during the same period.

\section{DISCUSSION}

Ten models were generated using the backward stepwise regression in SPSS. According to Table 2 models 7 and 8 were highly significant, reporting higher adjusted R-Squared of 0.739 and 0.738 respectively with lower standard estimates of error than the other models. Model 7 however, records the lowest standard error of estimation (5.508) against 5.522 in model 8. This study, in this respect, discusses model 7 which represents a higher probability of explaining the dependent variable, which is fatalities.

Table 4: Model 7

\begin{tabular}{|l|l|l|l|}
\hline Variable & $\begin{array}{l}\text { Standardised beta } \\
\text { coefficients }\end{array}$ & t-statistics & Significance \\
\hline Cellphone arrests & -0.257 & -1.655 & 0.117 \\
\hline Seatbelt arrests & -0.202 & -1.661 & 0.116 \\
\hline Speeding & 0.449 & 3.349 & 0.004 \\
\hline Unlicensed driver arrests & 0.857 & 4.425 & 0.000 \\
\hline Failure to produce a licence & -0.505 & -2.472 & 0.025 \\
\hline Number of registered vehicles & 0.279 & 1.746 & 0.100 \\
\hline Age 30 to 45 years & -0.156 & -1.041 & 0.313 \\
\hline
\end{tabular}

The variables 'cellphone arrests', 'seatbelt arrests', 'registered vehicles' and 'age 30 to 45' are all insignificant in the model, displaying a significance value higher than 0.05 (Table 4). The age variable is important because of its continued relevance to road safety research. The coefficients of all three variables show the expected signs and are therefore maintained in the model. The variables 'cellphone arrests' and 'seatbelt arrests' carry coefficients with negative signs demonstrating that law enforcement on these two factors has had a negative impact on the level of fatalities, representing a reduction in fatalities as a result of the road traffic police officers charging motorists with these offences. This is consistent with the findings of Redelmeier, Tibshirani and Evans (2003) who found that convicting motorists for road offences can reduce the relative risk of death for drivers and other road users by $35 \%$. Use of mobile phones while driving has been blamed for loss of concentration by drivers on the road leading to fatal accidents. This may include calling or texting, the latter being more dangerous. It has to be noted however, that there were few recorded actual cases 
of 'cellphone arrests'. Literature bears testimony to the fact that an increase in the use of seatbelts in most countries has improved road safety by reducing chances of fatalities in the case of accidents. The inverse relationship between seatbelt arrests and fatalities is an indication that use of seatbelts has since been increased because of enforcement of stricter road laws or rather the law enforcement units have been more effective. Further to that the increase in the number of vehicles registered in the country has resulted in the increase of road fatalities. This was expected because logic dictates that the more vehicles there are on the roads, the higher the probability of accidents occurring. Table 3 shows that on average 2600 vehicles are registered monthly which is quite high looking at the population and road network of the country. The country should consider investing in and encourage use of public transport.

Returning to Table 4, the statistics present the age category 30 to 45 years as the most represented group as far as driver licensing is concerned. Actually there are more drivers licensed in this category per month than any other group. This shows that most people in the country wait until they reach 30 years of age before applying for a driver's licence. It is therefore not surprising that according to this model the variable 'age 30 to 45 ' is inversely related to fatalities. This is consistent with the literature which has identified the young and the elderly motorists to be more prone to accidents than the middle age group. We can safely make the assumption that drivers in this category are more mature and in control of their behaviour than the young group which is more active and involved in socialising, which in most cases involves drinking.

The last three variables, which according to the model are significant, are 'speeding arrests', 'unlicensed drivers' and 'failure to produce a licence'. The first two variables have positive coefficients while the latter has a negative coefficient. Excessive speed has been blamed for fatal crashes. According to the model, speeding arrests have a high standardised coefficient of 0.449. Statistics for speed violations is higher than all road traffic law violations recording a monthly average of just over 3300 offences. This relationship suggests that arresting drivers for speeding increases the chances of road fatalities, which is inconsistent with the literature. In an interview with the traffic chief, he observed that since enactment of these stringent road laws there has been a decline in cases recorded whereas other indicators like number of accidents are not improving. According to him, traffic police officers are more prone to corruption and bribery than before. Unlicensed drivers also contribute to road accidents. According to the statistics people continue to drive without licences. The last variable indicates failure to produce a licence. This happens when law enforcers stop motorists in their regular patrols or road blocks and the latter fail to produce a licence. Convicting motorists of this offence shows it reduces fatalities. 


\section{LIMITATIONS OF THE STUDY}

Under-reporting and inability of the road safety stakeholders to follow cases after accidents is a major limitation of this study. The study covers a period of three years which may not reveal the impact of the policy especially in the view of limited resources available for enforcement. However the study's strength lies in the fact that it brings a fresh debate on whether punitive policies offer solutions to road traffic accidents and fatalities.

\section{CONCLUSION}

Enforcing the new traffic laws in Botswana has achieved little in the reduction of fatalities. What is evident though, from the findings, is that the increase in fines has not concomitantly impacted on fatalities. In fact the regression model rejected this factor as insignificant. The correlation statistics reveal a positive relationship between fines and fatalities. The model shows that unlicensed drivers continue to contribute significantly to road fatalities. According to the model 'speeding arrests' has a higher chance of explaining fatalities than 'number of registered vehicles'. On the other hand delaying licensing of drivers may offer a solution to road carnage. This may call for governments to increase the minimum age to qualify to get a driver's licence. Law enforcement agencies have to invest more effort in enforcing seatbelt law and laws against the use of mobile phones while driving. Further, because of limited resources (both financial and human in the form of law enforcement officers), the government should in the meantime intensify its public road safety campaigns. Future research should look into understanding the character of the driver as this would inform interventions especially preventive ones. Further to that an investigation on driver skillsset vis-à-vis the traditional driving schools' curriculum is recommended. Reliability of the findings of this study may be affected by the unavailability of reliable and up-to-date data. Most of the data was manually captured posing a challenge in management and retrieval. 


\section{REFERENCES}

Ali, G.A. 2010. Traffic accidents and road safety management: Comparative analysis and evaluation in industrial, developing and rich-developing countries. Paper presented the 29th Annual Southern African Transport Conference at CSIR ICC, Pretoria, South Africa from the 16th-19th of August 2010. Available from http://www.up.ac.za/academic/civil/ satc/storage/01_ga_ali_1.pdf (Accessed 19 September 2011).

Ansari, S., Akdaar, F., Mandoorah, M. \& Moutaery, K. 2000. Causes and effects of road traffic accidents in Saudi Arabia. Public Health. 114:37-39.

Aparicio, I.F., Arenas, R.B., Mira, M.J.M. \& Páez, A.J. 2011. The endurance of the effects of the penalty point system in Spain three years after. Main influencing factors. Journal of Accident Analysis and Prevention. 43(3):911-22.

Barengo, N.C., Mkamba, M., Mshana, S.M. \& Miettola, J. 2006. Road traffic accidents in Dar-es-Salam, Tanzania during 1999 to 2001. International Journal of Injury Control and Safety Promotion. 13(1):52-54.

Bjørnskau, T. \& Elvik, R. 1992. Can road traffic law enforcement permanently reduce the number of accidents? In: Accident Analysis and Prevention. 24:507-20.

Constant, A., Salmi, L.R., Lafont, S., Chiron, M. \& Lagarde, E. 2008. The recent dramatic decline in road motarlity in France: how drivers' attitudes towards road traffic safety changed between 2001 and 2004 in the Garzel cohort. Health Education Research. 23(5):848-58.

- 2009. Road casualities and changes in risky driving behaviour in France between 2001 and 2004 among particicpants in the Garzel cohort. Research and practice. American Journal of Public Health. 99(7):1247-53.

Elvik, R. 2010. A restatement of the case for speed limits. Transport Policy. 17:196-204.

Friedman, L.S., Hedeker, D. \& Richter, E.D. 2009. Long-term effects of repealing the national maximum speed limit in the United States. Research and practice. American Journal of Public Health. 99(9):1626-31.

Gainewe, M. \& Masangu, N. 2010. Factors leading to fatal crashes and fatalities in South African roads: 2005-2009. Paper presented at the 29th Annual Southern African Transport Conference at CSIR ICC, Pretoria, South Africa from 16-19 August 2010. Available from http://www.up.ac. za/academic/civil/satc/storage/02_m_gainewe.pdf (Accessed 19 September 2011). 
Jacobs, G., Aeron-Thomas, A. \& Astrop, A. 2000. Estimating global road fatalities. Transport Research Laboratory. Available from http://www.esafetysupport.org/download/eSafety_ Activities/Related_Studies_and_Reports/Estimating\%20Global\%20Road\%20Fatalities\%20 report,\%20TRL.pdf (Accessed 19 September 2011).

Mupimpila, C. 2008. Aspects of road safety in Botswana. Development Southern Africa. 25(4):425-35.

MVA Fund accident and injury report, Namibia. January-June 2009. Available from http:// www.mvafund.com.na/index.php?option=com_zoo\&view=category\&ltemid=50 (Accessed 19 September 2011).

MVA Fund, Botswana. Available from: http://www.mvafund.bw/mva-content.php?cid=85 (Accessed 15 September 2011).

Neeley, G.W. \& Richardson Jr., L.E. 2009. The effect of state regulations and truck-crash fatalities. Government, politics, and law. American Journal of Public Health. 99(3):408-15.

Peden, M., Scurfield, R., Slit, D., Mohan, D., Hyder, A.A., Jarawan, E. \& Mathers, C. 2004. The world report on road traffic injury prevention. World Health Organization. Available from: http://whqlibdoc.who.int/publications/2004/9241562609.pdf (Accessed 15 September 2011).

Pitso, J.M.N. \& Obot, I.S. 2011. Botswana alcohol policy and presidential levy controversy. Addiction. 106:898-905.

Redelmeier, D.A., Tibshirani, R.J. \& Evans, L. 2003. Traffic-law enforcement and risk of death from motor-vehicle crashes: case-crossover study. The Lancet. 361:2177-82.

Republic of Botswana. 2008. Road Traffic Act, Act 27 of 2008.

Richter, E.D., Friedman, L.S., Berman, T. \& Rivkind, A. 2005. Death and injury from motor vehicle crashes: a tale of two countries. American Journal of Preventive Medicine. 29(5):440-49.

Risa, A.E. 1992. Public Regulation of Private Accident Risk: The Moral Hazard of Technological Improvements. Journal of Regulatory Economics. 4:335-46.

Road Safety. World Bank. Available from: http://www.worldbank.org/transport/roads/safety. htm (Accessed 15 September 2011). 
Rothengatter, T. 1982. Effects of police surveillance and law enforcement on driver behaviour. Current Psychological Reviews. 2:349-58.

Seatbelt enforcement results in fewer deaths. 2009. Professional Safety. 22-23.

Shah, S.G.S., Khoumbati, K. \& Soomro, B. 2007. The pattern of deaths in road traffic crashes in Sindh, Pakistan. International Journal of Injury Control and Safety Promotion. 25(4):231-39.

Stewart, K. 2005. Dimensions of well-being in EU regions: do GDP and unemployment tell us all we need to know? Social Indicators Research. 73(2):221-46.

Tingvall, C. 2009. Vision Zero Drives Forward New Levels of Safety on Swedish Roads. Available from: http://www.roadtraffic-technology.com/features/feature64413/ (Accessed 02 February 2011).

Welki, A.M. \& Zlatoper, T.J. 2007. The impact of highway safety regulation enforcement activities on motor vehicle fatalities. Transport Research, part E. 43:208-17.

Yang, B.M. \& Kim, J. 2003. Road traffic accidents and policy interventions in Korea. Injury Control and Safety Promotion. 10(1-2):89-94.

Zajc, L. 1996. The role of traffic law enforcement in Slovene road safety system. Policing in Central and Eastern Europe: comparing first-hand knowledge with experience from the west. College of Police and Security Studies, Slovenia. Available from: http://www.ncjrs. gov/policing/rol663.htm (Accessed 05 February 2011).

Zietlow, G. 2006. The road safety cent: Management and financing of road safety in lowincome countries. Sector project, transport policy advisory services, Federal Ministry of Economic Cooperation and Development, Germany. 